San Jose State University

SJSU ScholarWorks

Faculty Publications

Hospitality, Tourism and Event Management

8-1-2011

\title{
Medical Travel Facilitator Websites: An Exploratory Study of Web Page Contents and Services Offered to the Prospective Medical Tourist
}

\author{
Daniel Cormany \\ University of Nevada, Las Vegas \\ Seyhmus Baloglu \\ University of Nevada, Las Vegas
}

Follow this and additional works at: https://scholarworks.sjsu.edu/hosp_mgmt_pub

Part of the Hospitality Administration and Management Commons, Tourism Commons, and the Tourism and Travel Commons

\section{Recommended Citation}

Daniel Cormany and Seyhmus Baloglu. "Medical Travel Facilitator Websites: An Exploratory Study of Web Page Contents and Services Offered to the Prospective Medical Tourist" Tourism Management (2011): 709-716. https://doi.org/10.1016/j.tourman.2010.02.008

This Article is brought to you for free and open access by the Hospitality, Tourism and Event Management at SJSU ScholarWorks. It has been accepted for inclusion in Faculty Publications by an authorized administrator of SJSU ScholarWorks. For more information, please contact scholarworks@sjsu.edu. 
Medical Tourism Facilitator Websites

An exploratory study of web page contents and services offered to the prospective medical tourist

\author{
Dan Cormany, MA, MS \\ University of Nevada, Las Vegas \\ Ph.D. Candidate \\ Harrah College of Hotel Administration \\ dancormany.medtourism@yahoo.com \\ Seyhmus Baloglu, Ph.D, CHE \\ Professor and Associate Dean For Research \\ Harrah Distinguished Chair \\ Tourism and Convention Department \\ Harrah College of Hotel Administration \\ seyhmus.baloglu@unlv.edu
}

\begin{abstract}
The growing trend of traveling outside of one's country for medical services, commonly known as "medical tourism" is expected to continue to grow exponentially in the next ten years (Keckley, 2008). With multiple destinations from which to select, and available information representing this type of travel being of variable reliability, many prospective medical travelers turn to the use of a "medical tourism facilitator", who perform a variety of trip coordination responsibilities for the medical traveler. These medical tourism facilitators, themselves a new phenomenon to support travel to various global regions, may operate within the traveler's home country or the destination region. This study explores the services offered on medical tourism facilitators' websites to the prospective traveler. Through the application of correspondence analysis, it was discovered that differences in both website content and in services offered varied by the continent upon which the facilitator operated. With little yet known as to the motivations of a medical traveler in the selection of a specific destination, these discovered differences may be a first insight into regional differences that may play a role in such destination selection.
\end{abstract}

\title{
1.1 INTRODUCTION
}

From before the days of ancient Rome, some individuals have chosen to travel to foreign lands for medical treatment (Weiermair \& Mathies, 2004; Marsek \& Sharpe, 2009), but the phenomenon has gained considerable momentum among Americans in the past four years (Edelheit, 2009). Popularly 
called "medical tourism", those participating in such travel may be seeking cosmetic enhancements, dental treatments, or increasingly, major or minor required surgery. Journeying to another country may be precipitated upon seeking specialty treatments, privacy, expedited medical attention, or, frequently, lower medical costs than available at home (Gahlinger, 2008; Woodman, 2008). Medical tourism is defined as "the act of traveling abroad to obtain medical care" (Keckley,2008, p. 4). The market drivers for medical tourism are cost savings, comparable or better quality care, and shorter waiting periods, thus quicker access to the care (Keckley, 2008). These "medical tourists" are alternatively referred to as "medical travelers", "medical value travelers", or "global healthcare travelers". Since there is no differentiation made in most current references, and the predominant current trade association has named itself the "Medical Tourism Association" (medicaltourismassociation.com, n.d.), this paper will use the terms interchangeably, but it recognizes that terminology in this new industry is currently unsettled.

It is notable that travel for medical care has, until recently, generally been from less developed nations to more developed countries (Horowitz, Rosensweig, \& Jones, 2007). In contrast to such travelers who are seeking the greatest expertise and technology available with little regard for cost, the recent development of "medical tourism" is dominated by individuals motivated to travel to acquire quality healthcare at prices more affordable to their circumstances. It is this second, more financiallyconstrained, medical traveler for whom the industry of medical tourism facilitation has developed. With the evolution of such travel, the significance of destination choice and area support services only grows in importance. Outside of the medical facility itself, the most usual provider of arrangements and accompanying support services is a new member of the tourism profession, called a "medical tourism facilitator" or "medical tourism facilitator". This facilitator may be located in either the traveler's home country or the host country, and firms offering these services have arisen across the globe. With a spontaneous generation of such firms in many locations in a very short period of time, the purpose of 
this study is to examine what sort of support these relatively new services are offering the medical traveler. This study utilizes content analyses to investigate web pages of medical travel facilitator websites to identify contents and services offered to the prospective medical tourist and to compare and contrast the information and services across businesses located on each of five continents.

As research has demonstrated that website content and marketing features significantly contribute to the effective delivery of messages, quality of products and services, and brand image in hospitality and tourism (Perdue, 2001), significant number of studies have examined the web content of hospitality and tourism organizations in terms of marketing and design elements, and provided practices from a single international location such as Turkey, Greece, Macau, Taiwan, and Australia, or the U.S.

These studies included, but not limited to, the content analyses of web sites of regional tourism organizations (Benckendorff \& Black, 2000), e-marketing strategies used by hotels (Sigala, 2001), webbased marketing and e-commerce by international hotel and tour wholesalers (Wan, 2002), luxury and upscale hotels' site design characteristics (interactivity, navigation, and functionality) and marketing practices on Internet (Baloglu \& Pekcan, 2006), web design and content of travel intermediaries such as convention and visitors bureaus (CVBs), travel agents, and destination marketing organizations(DMOs) (Ha \& Love, 2005; Roney \& Ozturan, 2006, Kim, Yuan, Goh \& Antun, 2009), and image building and branding elements used on travel and U.S. state tourism websites (Lee, Cai \& O'Leary, 2006; Choi, Lehto \& Morrison, 2007).

Medical facilitation is a growth industry, as the number of US citizens traveling abroad for medical services has been doubling each year since 2003, and its expansion was projected last summer to continue to potentially over 23 million by 2017 (Keckley,2008). While world tourism in general is predicted to contract 7.9\% in 2009 due to worldwide economic circumstances (Myers, 2009), Deloitte issued a revised projection in fall, 2009, projecting more modest growth; however, increases of 
outbound US travelers by 35\% per year are still projected through 2012 (Keckley, 2009). This recent iteration of medical tourism is attributed to Thailand's promotion of such health services in 1998 when its economy caused both its medical and hospitality industries to languish, so it merged its combined infrastructure capabilities to market to foreign visitors in need of treatments (Gahlinger, 2008).

\subsection{LITERATURE REVIEW}

\section{2..1 Medical Tourism and Facilitators}

From that recent metamorphosis in health travel as more travelers from more developed nations journey to lesser developed ones for care, and in response to demand, the number of destinations promoting medical services has greatly expanded to over 50 nations (Gahlinger 2008; Schult, 2006; Woodman, 2008), with some targeting a specific treatment focus while others are offering a wide-ranging scope of medical services (Bookman \& Bookman, 2007; Gahlinger, 2008; Hancock, 2006; Woodman, 2008). There are now destinations marketing to such travelers on every one of the world's continents save Antarctica, giving potential travelers a wide array of selection possibilities. This has been quietly supported by some health insurance providers; as of spring, $2009,11 \%$ of all employers in the US providing health coverage to their employees provide medical tourism as an option (Stephano and Edelheit, 2009).

It is generally asserted, but as of yet unproven, that the driving motivator for such travelers is cost savings. Yet, that explanation is a dull instrument by which to explain the totality of this phenomenon, for it may potentially explain the most common "push" factor spurring the consideration of such travel, but it does little to explain a specific destination's appeal, or the "pull" factors (Dann, 1977). Nor does it account for the potential for combining surgery with a restful vacation, as is frequently hyped in the popular media when it is reporting on medical tourism, or the desire for medical 
procedures not available in the United States. For a trend that has such steep and healthy growth projections, little is yet known about the "medical tourist" who journeys outside of the country for medical treatment.

The void of knowledge receives little relief from studies of other forms of tourism as it is not yet demonstrated that individuals traveling to receive health care will necessarily share the same motivations, priorities, and criteria for site selection as those who travel either for leisure or business purposes. Also unexplored is how this purpose of travel, which is the first tourism genre to have fully started in its modern form after the existence of the internet, has been facilitated, perhaps even essentially created, through the worldwide web.

However, studying medical travelers presents some unique challenges not faced in other tourism research. Most notably, due to the involvement of medical treatment, many of the sources which might help identify this cadre of individuals for study are legally bound to confidentiality. This especially includes hospitals, doctors, and medical tourism facilitators (similar to medical travel agents), who would otherwise be the clearest sources for contacts.

Thus, medical travelers must self-identify in order to be studied, and this poses the probability of a skewed representation of the population. This seems especially true of the traveler for major surgery, as the anecdotal stories of such surgical and travel reports found in literature and on the internet nearly all indicate a positive and successful experience (an example of such literature is Grace, 2007). In these reports, the traveler frequently becomes an evangelist for medical travel, providing interesting insights but not material from which generalizations may be built.

Studies of leisure traveler motivation identify self-esteem enhancement and social approval as factors in both the decision to travel and in selecting a destination (Sirgy \& Su, 2000). Such motives may 
enhance the likelihood of a leisure traveler discussing his or her experiences. For the medical tourist, however, it is not clear that such motivations are at the forefront, and the sensitivity of health needs may be a limiting factor regarding who will be willing to discuss their experiences. Indeed, medical tourism facilitators report that generally somewhere within the potential medical tourist's circle of friends and family there will exist some individuals who voice concern and sometimes heated opposition to the idea of overseas travel for medical treatment (Marsek \& Sharpe, 2009), thereby encouraging even greater privacy and selectivity in choosing with whom the experiences will be discussed. Even those returning from successful surgery commonly are met with skepticism (Marsek \& Sharpe, 2009), so hesitation to discuss one's experience is an understandable result.

Additionally, some forms of medical treatment, rather elective or necessary, may be such that individuals may wish them to remain confidential. Hysterectomies, prostate surgery, or cosmetic operations (Marsek \& Sharpe, 2009) are only a few examples of procedures for which previous travelers may hesitate to share their medical travel experiences.

Attempting to learn of this population's needs and expectations might therefore initially be approached from the point of view of the service provider. Hospitals and hotels each play important roles in the experience of the medical tourist, but each has a specific part it contributes. Of broader scope is the medical tourism facilitator, who is in contact with the traveler from the planning stages of the trip through the travel, and as follow-up upon the guest's return home.

A limited number of medical tourism facilitators have been serving in such a role for up to 20 years, primarily for cosmetic surgery travelers, but the majority of such facilitators have been in business less than 8 years. Judging from the websites of such medical tourism facilitators, some are past medical travelers themselves, others approach the role as an outgrowth of travel agency work, and still others appear to be more medically based, with medical personnel as key staff members. 
2.1.2 Internet and Medical Tourism

Perhaps due to the scattered demographics of the potential medical traveler, or perhaps because the growth of modern medical travel has developed subsequent to the establishment of the internet as a travel information source, the foundation of medical facilitation is found in an online presence. Patterson (2007) found the internet second only to friends as a source of general travel information, and in light of the attitudes often demonstrated by friends toward medical tourism, the internet potentially serves an even more central role.

Utilization of the internet is especially true of leisure travelers from the United States, as Hyde (2006) reports the US planner relies more heavily on the internet for travel planning than counterparts from Asia, Australia or Europe - a finding duplicated by Lee, Soutar and Daly (2007). Reliance on the internet for US medical travelers, may be even more pronounced, as no primarily brick-and-mortar establishments have been located focusing on the potential medical tourist; all medical facilitation services are marketed through the internet and their initial services are facilitated via the web.

While Oorni (2004) found that the internet was a complementary information source to other travel information sources for the majority of consumers searching for travel purposes, for the medical traveler there are few other sources of information available to them other than telephoning sources identified on the internet. Even workers in the US medical community remain unknowledgeable of the rudimentary basics of medical tourism, and within that community there are several whose judgment may be suspected of national proprietary leanings (Stephano, 2008).

Five guidebooks have been published in the popular press, three in the last year, providing the only non-web-based information that has been located to guide the prospective medical tourist. These books include: The Medical Tourism Travel Guide, by Gahlinger, 2008; The Complete Medical Tourist, by 
Hancock, (2006); The Complete Idiot's Guide to Medical Tourism, by Marsek \& Sharpe, (2009); Beauty from Afar: A Medical Tourist's Guide to Affordable and Quality Cosmetic Care Outside the U.S, by Schult, (2006); and Patients Beyond Borders, by Woodman (2008). Also consulted was the list of medical tourism facilitators on the medtripinfo website (http://medtripinfo.com/research/travel_facilitators).

Drawing further on the research of internet search characteristics for the leisure traveler, Wolfe, Hsu and Kang (2004) indicated a desire by travelers for "one-stop shopping" (p. 53); whether such a desire is prevalent among prospective medical tourists is untested. However, there seems to be such an assumption made with many of the medical tourism facilitator websites.

With little academic research from which to draw, it is suggested that one starting point for exploring medical tourism is to investigate what information and services the medical tourism facilitator has identified as important to the medical traveler. It is posited that, as business people seeking to cultivate a market, these medical tourism facilitators may provide some early indication of what they believe to be important to the prospective medical traveler. By understanding what is currently offered, a foundation is created from which to continue to examine this rapidly growing trend in travel and health care.

\subsection{METHODOLOGY}

\subsubsection{Selection of Medical tourism facilitators' Websites}

A search for online medical tourism facilitators returns a plethora of sites, of apparently varying credibility. In this research, 70 medical tourism facilitator websites were identified for analysis. These 70 were selected as those named in one or more of five current guidebooks published for prospective medical tourists noted above. Thirteen of these 70 websites were found to no longer in existence when 
the site was visited, perhaps demonstrating the volatility of this new market and leaving 57 sites from which to draw data.

Of the 57 sites, 24 are based in North America, 11 in Asia, 8 in Europe, 8 in Central or South America, and 6 in Africa. Those based in North America are focused on assisting primarily United States travelers in planning surgeries outside of the country, while those in the other destinations were designed to help travelers come to the region they represent. Since the internet is a constantly changing entity, all sites were visited within a one month period in April, 2009, to capture a snapshot of each site's offerings within a specific timeframe. All websites have English versions, while some have several additional language options.

It may be noted that some significant medical tourism locations, such as Singapore and Thailand, are not represented on this list. Neither site had medical tourism facilitators noted on any of the sources used to identify such sites. This may be due to the extensive international patient services offices common in both countries, whose staff provide most the services normally associated with medical tourism facilitators.

\subsubsection{Selection of Content Items}

For each website visited, evaluation was made on content of the website and the services offered by its owners. No judgment was made as to the website's design or functionality, no measurement was attempted to judge site layout, usability, or appeal. Items evaluated were measured on a nominal "present / not present" scale, eliminating the variability of qualitative assessments.

Sites were judged by two sets of criteria. The first was information present on the site. An initial list of 12 items included:

email contact 
telephone number

mailing address

information request form

maps of destinations served

hospital selection

notation of hospital accreditation

listing of medical procedures available

estimated treatment costs

past traveler testimonials

links to informational websites

whether the date of the last webpage update was provided.

Compilation of this list was informed by items used by Baloglu and Pekcan (2006) in their study of internet sites of upscale Turkish hotels, and website analysis done by Choi and Morrison (2005) and Park, Gretzel and Sirakaya-Turk (2007), although modifications were necessary to accommodate the medical aspects of such travel (Gahlinger, 2008, Woodman, 2008, Bookman \& Bookman, 2007, Hancock, 2006, Schult, 2006).

Throughout the process of visiting sites, attention was paid to potential other categories not included on this original list. One other emerged to be included; that of information for employers considering the addition of medical tourism to their employer-provided health options. Otherwise, the list proved to be inclusive of the information found on most the websites. 
The second set of criteria was a listing of services offered by the firm. The guiding principle used was simply whether the site mentioned that such services were facilitated by them. These 10 service areas included:

air travel

ground transportation

hotel accommodations

translation services

concierge services

site seeing options

arrangement of medical appointments

transfer of medical records

provision of aftercare support services (during recuperation while still in the country of the medical treatment)

provision of an international cell phones

Also included in this list was an assessment of the number of countries with which the facilitator coordinated services. For this latter item, the dichotomous rating was either that services were offered to one destination country, or more than one destination country.

It is important to note that in order to meet the criteria that a facilitator did offer a service, it needed to be mentioned on the website available for all visitors to review. Some medical tourism facilitator models require paid membership prior to accessing all information, but if the promise of such 
information was made on the public webpage, the facilitator was shown in this site review as offering such service. Conversely, information possibly available to paid members but not noted on the public webpage went unidentified and is not reflected in the data presented here.

The list of potential services was constructed as a compilation of potential services available from medical tourism facilitators, again using Gahlinger (2008), Marsek \& Sharpe (2009), and Woodman (2008) as sources. As with the first criteria list, attention was given to any additional services not on the original list, and it was discovered that financing arrangements were offered by several companies, so this, too, was added to the compilation. No other additional services were found to be offered by any of the facilitators, indicating that the list of services appears to be a comprehensive one.

\subsubsection{Geographic Areas Covered}

Sites based out of Central and South America included one in Argentina, three in Brazil, two in Costa Rica, one in Panama, and one in Venezuela. European sites included three in Germany, one in Croatia, one in the Czech Republic, one in England, one in Hungary, and one in Spain. Asian sites were represented by six in India, one in Israel, two in Malaysia, one in Singapore, and one in Turkey. Finally, African sites were based out of five in South Africa and one in Tunisia. Some of these sites worked with only one hospital or clinic, while others claimed to facilitate travel and treatment at several facilities. Most worked only with clinics or hospitals within their national borders. Assignment of the geographic location was based upon the mailing address provided on the website. This is not without its limitations, as it is possible facilitators are legally established in a country for legal or financial protections, but focusing their service provisions in other areas; however, short of global incorporation documentation research, it was felt that mailing addresses were the most reasonable way of establishing their home base of operations. 
United States businesses were scattered among the states, with four in California, three in Texas, two each in Colorado, Florida, New York, and one in each of the following: Arizona, Illinois, Maryland, Massachusetts, Michigan, Minnesota, Missouri, Nevada, North Carolina, South Carolina, and Vermont. All claimed to work with several hospitals, and the majority of the US-based websites worked with facilities in more than one country.

\subsubsection{Data Analysis}

Due to the multiple types of services and information, a useful way of comparing en mass the website information and services of different regions is a method called correspondence analysis. This procedure is especially useful when data are nominal (Clausen, 1998), as in this case, as it provides an "easy-to-interpret perceptual mapping tool that is appropriate for analyzing categorical data (Javalgi, Whipple, McManamon \& Edick, 1992, p. 35). It provides a way to see patterns, and judge "inertia" (which is similar to variance in principal components analysis) that is contributed by the principal axes. Additionally, the inertia associated with each dimension may be broken into proportions explained by the various points (Lee, Soutar, and Daly, 2007). These proportions measure the "quality" of the results obtained for a particular row or column (Hoffman \& Franke, 1986). As detailed by Hoffman and Frank, such a quality number is "the relative contributions to inertia...the relevant squared correlations and the sum of these correlations across dimensions" ( $p$ 168). While the interpretation is subjective, the higher the quality number (from 0 to 1 ), the higher assurance there is that the results are a good representation of that aspect of the data (Lee, et al, 2007)

By using symmetric graphing, the same relative values are used in all axes, permitting a comparison of rows and column values at the same time. The nearer a row or column item is to the intersection of the axes, the less relative difference it represents compared to other row or column items a greater distance from the intersection, and the closer a column value is to a row value, the 
greater interrelatedness do the components share. While similar distances of one characteristic from two others may be interpreted as a relatively similar degree of difference of that first characteristic to the others, this difference in distance is not an arithmetic one. Therefore, conclusions may not be suggested that a certain characteristic is, for instance, "twice" or "half" as likely as another due to plotting alone, but relationships may be posed by those in proximity to each other

A particular benefit of correspondence analysis is the insight it can suggest by how items are grouped along an axis. By examining each axis, it may be possible to see certain themes which explain item orientation along one axis. This observed relationship is not possible by studying only individual item percentage scores, and represents one of the strengths of correspondence analysis.

\subsection{RESULTS AND DISCUSSION}

When the 24 US medical tourism facilitators are compared to the combined totals of the other 33 facilitators from the other four continents, a few sizeable gaps between the two groupings can be identified. US facilitators are much more likely to include location maps, hospital accreditation explanation, and information for employers than the facilitators based in other locations. In terms of services, US facilitator websites do not mention assistance in arranging medical appointments near as often as other continents, but they are much more likely to be providing services to more than one destination country, to assist in the transferring of medical records, and of offering international cell phones to permit calling back to the United States.

However, since the data is nominal, the magnitude of these differences cannot be compared as interval data would permit. Additionally, these raw percentages do not provide a picture of how one service may be related to another, or more closely associated with one region than another. 
4.1.1. Webpage Feature Comparison

Correspondence analysis was initially run using all webpage feature data collected, resulting in figure 1.

<insert figure one here>

<insert table one here>

The analysis of this contingency table shows a $55.12 \%$ contribution from Axis 1 , and a $29.00 \%$ contribution from Axis 2, for a total explained difference of $84.12 \%$. In exploring a third dimension, the contribution of a third axis is $9.68 \%$, below the advised level of $20 \%$ in order to be included as an additional dimension (Hair, Black, Babin, Anderson, \& Tatham, 2006). Therefore, this model is presented as a two dimensional.

The quality numbers for the five regions under review are: North America, .998; Central and South America, .349; Europe, .686; Asia, .783; and Africa, .985, demonstrating that the two regions most different from the other three are North America and Africa. Examining the themes of the two axes suggests that axis one generally has aligned web content from more personal (such as personal testimonials) to more generalized information (such as information for employers). Axis two may be considered in terms of soft (testimonials) to hard information (cost estimates). Using this interpretation, Asia, Europe and Central/South America all lean toward personalized, hard information, while Africa emphasizes soft, personal information, and the US has a greater tendency toward more generalized information, balanced between the variability of hard or soft.

However, because so many of the webpage items are commonly shared with all countries as they lie near the intersection of the two axes, the greatest illustrative power of the figure is in showing three areas in which North American medical tourism facilitator websites are notably different from 
others. Those are the areas of noting hospital accreditation standings, providing information for employers considering the inclusion of medical tourism in their health care plans, and providing location maps of the regions being served by the facilitator.

These may not be surprising, as the prime source for international hospital accreditation is based in the United States (jointcommissioninternational.org, 2009), the soaring costs of medical care has US employers increasingly interested in the cost saving options of medical tourism (Edelheit, 2009; Gahlinger, 2008; Marsek \& Sharpe, 2009), and since the US medical tourism facilitators are far more likely to be providing services to multiple countries, location maps for purposes of comparison might be of greater value for the US facilitator sites.

The provision of cost estimates is more closely aligned with the Asian websites, which may be a marketing factor as a result of the steeply lower prices provided by hospitals especially in India, Malaysia and Thailand. Africa has positioned itself primarily as a cosmetic surgery destination, frequently linking its offerings to safari and site-seeing options, and emphasizes more the testimonial aspects of past patients than other regions.

Most of the other webpage features assessed are clustered closely enough to one another and to the intersection of the axes to make generalizations difficult. It appears that all regions have somewhat similar ideas of what needs to be included in their web pages; the two areas that most differ between North America and all other regions is an US emphasis on hospital accreditation - a change that could easily be made by other websites if accreditation proves to be as important an element as apparently believed by the facilitators in North America. The second competitive advantage held by North America may be more difficult for other regions to emulate, as provision of employer information requires a fairly intimate understanding of the workings of American business, so this may remain the primary purview of North American facilitator websites. On the other hand, it is notable that the listing 
of specific hospitals with which a facilitator works is the webpage content item most distant from North American websites.

\subsubsection{Services Noted on Webpage}

The correspondence analysis of the services noted as offered on the websites demonstrates greater variability, and some clear grouping of services by region.

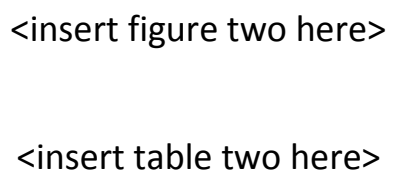

The analysis of this contingency table shows a $65.6 \%$ contribution from Axis 1 , with North American websites having the greatest impact on this axis, and European websites having the greatest contributory portion to an overall $19.31 \%$ contribution from Axis 2, for a total explained difference of $84.12 \%$. Once again, the third dimension is significantly below the advised level of $20 \%$ in order to be included as an additional dimension (Hair, et al, 2006). Therefore, this model is also presented as a two dimensional.

The quality numbers for the five regions under review for service offerings are: North America, .995; Central and South America, .693; Europe, .929; Asia, .563; and Africa, .787, demonstrating that the two regions most different from the other three are North America, and by the slightest of margins, Europe over Africa. Examining the themes of the two axes suggests that axis one generally has aligned service offerings from the left side emphasizing services that help the potential traveler adjust to the idea of traveling for medical treatment and preparing for the trip to the right side placing a greater emphasis on services to be provided once the traveler is in the destination country. The second axis, it is suggested, runs from one end emphasizing personal involvement with the traveler in the destination country to one which places greater importance on coordination of logistical details for the traveler. 
North American agencies clearly are more frequently providing services to multiple countries than any other region. This may be explained as these agencies are primarily servicing outbound travelers, while the other regions are generally dedicated to one country or area. North American facilitators also are more likely to offer assistance in transference of medical records, in providing destination area cell phone support, and in working with clients in financing options to pay for both travel and medical costs. Finally, North American medical tourism facilitators are slightly more associated with booking air transportation than other regions, where the emphasis is on ground transportation coordination.

Central and South America have two services in its cluster. Concierge services for travelers while in the destination country, and personal aftercare arrangements that support and follow-up after an individual is released from hospital care are both highly personal services in which the region seems to be trying to distinguish itself.

Europe is situated on the figure as closest to those services of arranging medical appointments and coordinating site-seeing opportunities. With the abundance of low energy, sophisticated site-seeing possible in many European destinations, and quality ground transportation options, and generally an emphasis on less critical surgical offerings, site-seeing may be seen by European providers as an important element of their appeal. The stated emphasis on arranging medical appointments for its clients is less easily hypothesized, yet this service remains most centrally in the European region of the figure.

Translation services may be a critical factor for US medical travelers, or be of little consequence, depending upon the destination chosen. English is commonly spoken in India, Malaysia, Singapore, and South Africa and so may be no hindrance to the selection of any of those countries. Conversely, the native languages most different from English are the Asian languages, so translation services may be an 
especially critical consideration for prospective medical travelers to countries such as Korea, Thailand, China, Vietnam, etc. This variability does place translation services closest to the websites representing the Asian regions, somewhat evenly split between Europe and Central/South American clusters. Indeed, the other services also most closely associated with Asian websites, such as ground transportation and hotel arrangements, may be more adequately explained as services common to all three regions, and Asia's position on the figure more demonstrates a lack of distinguishing service emphases.

Finally, Africa shows no distinguishing service elements, remaining approximately equidistant with Europe and Central/South America in ground transportation, hotel reservations, and inexplicably, translation services.

\subsection{CONCLUSION}

The scope of this study was to explore the information provided to prospective medical tourists and the services offered to them by medical tourism facilitators currently in business. While care was taken to identify some of the better facilitators currently coordinating medical travel trips, the demise of over $12 \%$ of the facilitators identified by recent guidebooks demonstrates the volatility and change washing through the concept of medical tourism currently. Results presented should be viewed as a snapshot of current services, as identified by medical tourism facilitators as desirable offerings. Since the information is from the provider and not the traveler, there is no assurance that the web contents or the services offered are those desired by the prospective medical tourist.

However, the results of this correspondence analysis indicate that both in website information and services offered, US facilitators are different from the counterparts in Asia, Africa, Europe or Central/South America. North American facilitators tend to favor the provision of generalized information via their website, focusing on factors that help the prospective traveler adapt to the idea of 
travel for medical services and understanding what to expect, while the other continents focus on more personalized information framed by the traveler's time in the destination country, rather than preparations for such travel. Since US residents are less acclimated to the concept of international travel for medical procedures than are those from many other countries, the US is viewed as the sleeping giant for medical tourism by many destination countries (Edelheit, 2009), the marketing message conveyed by US facilitators may resonate well with the US traveler.

Europe and Central/South America seem quite similar in their approach to providing web content in a more personalized way, but these similarities end in the provision of services, where Europe values organization and arrangement of details while Central/South America emphasizes interpersonal dynamics during a visit to its region.

The findings are limited to websites selected and content items included in the study as well as how they were measured. The study focused on absence or presence of the services rather than an assessment of website quality. There were also some items considered, but could not be further investigated as explained earlier in the paper.

One national vagary was discovered during this evaluation. Some countries have laws restricting the promotion of medical services, limiting some items that may be included in websites based in those areas. For instance, the laws of Germany specifically limit details of the "therapeutic and diagnostic qualifications...[and] the technical equipment...[and] the methods of a hospital...or a doctor [and his or her] specialization" (Germanmedicine.net, 2009). While no impact of this law was perceived in assessing the criteria specified for this study, it does highlight the potential existence of international variability of laws which may impact the content of websites. 
There appear to be two possible directions for an area's medical tourism facilitator to choose to develop. The uniqueness of service emphasis shown by North America, Europe, and Central/South America suggests marketing strengths each might continue to develop to distinguish it from its competition with other regions.

However, for Asia, which shows no specific service focus but rather holds the most balanced position to the greatest number of services, further development of some of the North American service attributes could aid it in assuming an even more central position within the figure. Whether competitive advantage can be best achieved through cultivation of a unique service emphasis, or whether medical tourists, when considering something as personal and critical as one's health, want a balanced and comprehensive set of offerings, is a question that begs for research exploration with prospective medical travelers.

Many other questions remain to be answered, not the least of which is how to identify a representative sampling of the medical tourist population - both prospective and past travelers - from which to investigate information and service desires.

Such a sampling would also permit a vast array of additional medical tourism topics to be explored. A question rich in potential is how internet usage in trip planning differs between the leisure and the medical traveler. Lee, Soutar and Daly (2007) indicate that part of the enjoyment of travel is the planning and anticipation of the travel. Seeking out of information becomes anticipatory pleasure, so greater time is devoted to the activity. Individuals traveling for needed medical treatment, however, may bring considerably different affective factors to their internet usage in trip planning.

Additional questions involve whether early innovators in internet usage are also more apt to consider the relatively new approach to medicine via overseas travel. Kah, Vogt, and MacKay (2008) 
found that to be true of leisure travelers making arrangements via the internet, but medical travel is significantly different as to warrant specific study on this matter.

Whether "one stop shopping" for medical tourism arrangements is considered a strength or an indication of lack of specialization in the critical realm of health care is a question that is vital for medical tourism facilitators to know, as is the criteria by which a medical tourism facilitator is selected. This criteria may vary, depending upon the type of procedure desired, suggesting that research might be eventually segmented to focus on those seeking major surgery, minor surgery, optional procedures, diagnostic procedures, alternative treatments or wellness services (Cormany, 2008).

Even more basic is the process by which the decision to travel overseas for medical procedures is made. Both push and pull elements (Dann, 1977) of the motivational question deserve exploration, as does the order in which the decisions are generally made - whether country, hospital, facilitator, or other element weighs most greatly in the selection of a destination is information that would help not only medical tourism facilitators but all related hospitals, firms, clinics, hotels, and destination managers in crafting their messages and designing their services and facilities.

With the projected growth of medical tourism, the need to know is urgent. This study has attempted to summarize the various approaches used by medical tourism facilitators, but this is only a small handhold in the search for understanding into this phenomenon. It is hoped that through the information it has identified, research may proceed to better understand the desires of the prospective medical tourist. 
Figure 1: Webpage Contents

\section{Symmetric Plot of Web Contents}

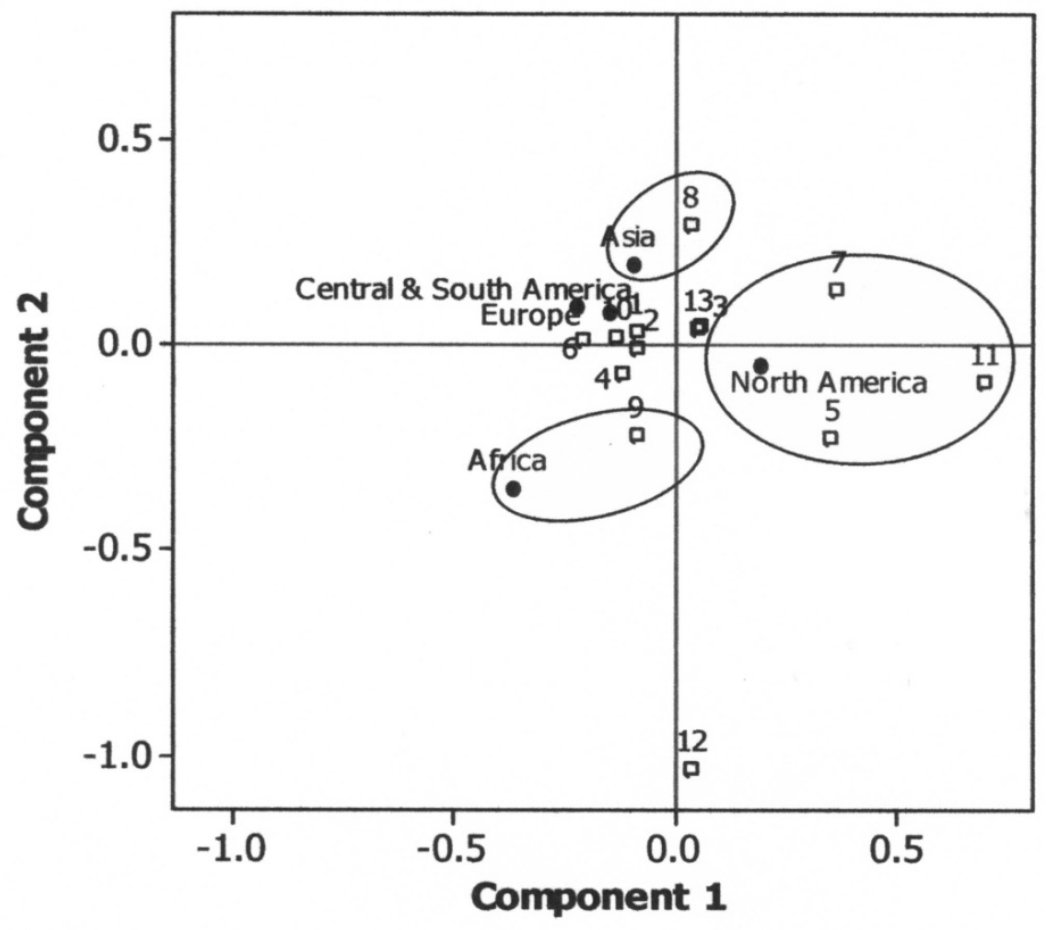

Circles represent continents;

squares represent individual webpage contents;

1. Email

2. Phone

3. Address

4. Information Request

5. Location Maps

6. Hospitals

7. Hospital Accreditation
8. Estimated Costs

9. Past Patient Testimonials

10. Available Medical Procedures Listed

11. Employer Information

12. Last Updated Date

13. Links to Other Web Pages

Table 1 - Webpage Contents

\begin{tabular}{|l|l|ll|ll|}
\hline Axis of Web Contents & Inertia & \multicolumn{2}{|l|}{ Proportion } & \multicolumn{2}{l|}{ Cumulative } \\
\hline 1 & .0402 & $.5512(55.12 \%)$ & $.5512 \quad(55.12 \%)$ \\
\hline 2 & .0212 & $.2900(29.00 \%)$ & $.8412 \quad(84.12 \%)$ \\
\hline 3 & .0071 & $.0968(9.68 \%)$ & $.9380 \quad(93.80 \%)$ \\
\hline 4 & .0045 & $.0620(6.20 \%)$ & $1.000 \quad(100 \%)$ \\
\hline
\end{tabular}


Figure 2: Services Offered

\section{Symmetric Plot of Services Noted, No. of Countries Offered}

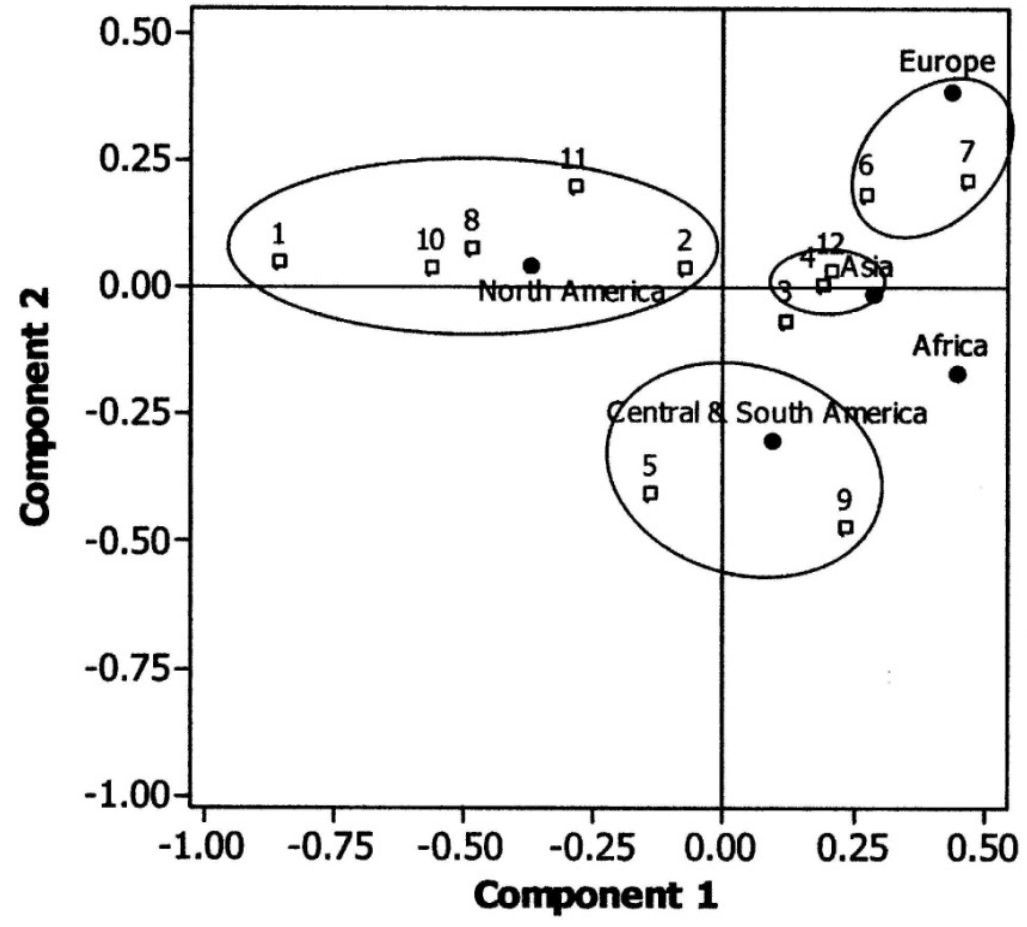

Circles represent continents; squares represent individual services offered;

1. One or Multiple Countries Served

2. Air Transportation

3. Ground Transportation

4. Translation Services

5. Concierge Services

6. Site-Seeing Options
7. Arrange Medical Appt.

8. Transfer Medical Records

9. Aftercare Services in Country

10. International Cell Phone/Calling Services

11. Financing Services

12. Hotel Accommodations

Table 2 - Services Offered

\begin{tabular}{|l|l|l|l|l|}
\hline Axis of Services Noted & Inertia & \multicolumn{2}{|l|}{ Proportion } & \multicolumn{2}{l|}{ Cumulative } \\
\hline 1 & .1219 & $.6560(65.60 \%)$ & $.6560 \quad(65.60 \%)$ \\
\hline 2 & .0359 & $.1931 \quad(19.31 \%)$ & .8491 & $(84.91 \%)$ \\
\hline 3 & .0170 & $.0917(9.17 \%)$ & .9408 & $(94.98 \%)$ \\
\hline 4 & .0110 & $.0592(5.92 \%)$ & $1.000 \quad(100 \%)$ \\
\hline
\end{tabular}




\section{References}

Baloglu, S. and Pekcan, Y.A. (2006). The website design and internet site marketing practices of upscale and luxury hotels in Turkey. Tourism Management. 27. 171-176.

Benckendorff, P.J. \& Black, N.L. (2000). Destination marketing on the Internet. A case study of Australian Regional Tourism Authorities. The Journal of Tourism Studies 11(1), 11-21

Bookman, M.Z. \& Bookman, K.R. (2007). Medical tourism in developing countries. New York: Palgrave MacMillan.

Choi, S. and Morrison, A.M. (2005). Website effectiveness for bricks and mortar travel retailers. Anatolia: An International Journal of Tourism and Hospitality Research. 16(1). 63-78.

Choi, S., Lehto, X.Y., \& Morrison, A. M. (2007). Destination image representation on the web: Content analysis of Macau travel related websites. Tourism Management, 28(1), 118-129.

Clausen, S. (1998). Applied Correspondence Analysis. Thousand Oaks, CA: Sage Publications.

Cormany, D. (2008). Taking a pulse on potential medical tourism destinations: The hospitality and tourism industries. Medical Tourism Magazine. 7(November, 2008). 34-37.

Dann, G. (1977). Anomie, ego-enhancement and tourism. Annals of Tourism Research. 4. 184-194.

Douglas, N. (2001). Travelling for health: Spa and health resorts. Special interest tourism (ed. Douglas, N., Douglas, N., \& Derrett, R.) Milton, Australia: John Wiley and Sons.

Edelheit, J. (2009). The effects of the world economic recession on medical tourism. Medical Tourism Magazine. 9. 22-24. 
Gahlinger, P. (2008). The medical tourism travel guide. North Branch, MN: Sunrise River Press.

Germanmedicine. (2009). Retrieved April 20, 2009: http://germanmedicine.net.

Grace, M.A. (2007). State of the Heart. Oakland, CA: New Harbinger Publications.

Hair, J.F., Jr., Black, W.C., Babin, B.J., Anderson, R.E. \& Tatham, R.L. (2006). Multivariate Data Analysis (Sixth edition). Upper Saddle River, NJ: Pearson Prentice Hall.

Ha, M. \& Love, C. (2005). Exploring Content and Design Factors Associated with Convention and Visitors Bureau Web Site Development: An Analysis of Recognition by Meeting Managers. Journal of Convention \& Event Tourism, 7(1), 43-59.

Hancock, D. (2006). The Complete Medical Tourist. London: John Blake.

Hoffman, D.L., \& Franke, G.R. (1986). Correspondence analysis: Graphical representation of categorical data in marketing research. Journal of Marketing Research. 23(3). 213-227.

Horowitz MD, Rosensweig JA, Jones CA. Medical tourism: globalization of the healthcare marketplace. Medscape General Medicine 9(4):33, November 13, 2007.

Hyde, K. (2006). Contemporary information search strategies of destination-naïve international vacationers. Journal of Travel \& Tourism. 21(2/3). 63-76.

Javalgi, R.G., Whipple, T.W., McManamon, M.K., \& Edick, V.L. (1992). Hospital image: A correspondence analysis approach. Journal of Health Care Marketing. 12(4). 34-41.

JCI. (2009). Retrieved April 20, 2009 from Joint Committee International website: http://www.jointcommissioninternational.com 
Kah, J.A., Vogt, C. \& MacKay, K. (2008). Online travel information search and purchasing by internet use experiences. Information Technology \& Tourism. 10. 227-243.

Keckley, P.H. (2008). Medical Tourism: Consumers in Search of Value. Washington, DC: Deloitte Center for Health Solutions.

Keckley, P.H. (2009). Medical Tourism: Updates and Implications. Washington, DC: Deloitte Center for Health Solutions.

Kim, Y. H, Yuan, J., Goh, B., \& Antun, J. M. (2009). Web Marketing in Food Tourism: A Content Analysis of Web Sites in West Texas. Journal of Culinary Science \& Technology, 7 (1), 52-64

Lee, G., Cai, L.A., \& O’Leary, J. T. (2006). WWW.Branding.States.US:An analysis of brand-building elements in the US state tourism websites. Tourism Management, 27(5), 815-828

Lee, J. Soutar, G., \& Daly, T. (2007). Tourists' search for different types of information: A cross-national study. Information Technology \& Tourism. 9. 165-176.

Marsek, P. \& Sharpe, F. (2009). The Complete Idiot's Guide to Medical Tourism. Indianapolis, IN: Alpha Books.

MTA. (2008). First World Congress on Medical Tourism. Unpublished conference presentations. San Francisco, CA: Medical Tourism Association.

Minitab 15. (2006). Minitab Statistical Software (Version 15.1.0.0). [Computer software]. State College, PA: Minitab, Inc.

Myers, G.N. (2009). Caribbean confab stresses cooperation during 'perilous time'. Travel Weekly. (April 27). 59. 
Oorni, A. (2004). Consumer objectives and the amount of search in electronic travel and tourism markets. Journal of Travel \& Tourism Marketing. 17(2/3). 3-14.

Park, Y.A., Gretzel U. \& Sirakaya-Turk, E. (2007). Measuring web site quality for online travel agencies. Journal of Travel \& Tourism Marketing. 23(1). 15-30.

Patterson, I. (2007). Information sources used by older adults for decision making about tourist and travel destinations. International Journal of Consumer Studies. 31. 528-533.

Roney, S. A. \& Ozturan, M. (2006). A Content Analysis of the Web Sites of Turkish Travel Agencies. Anatolia, 17(1), 43-54.

Shult, J. (2006). Beauty from afar: A medical tourist's guide to affordable and quality cosmetic care outside the U.S. New York: Stewart, Tabori \& Chang.

Sigala, M. (2001). Modeling e-marketing strategies: Internet presence and exploitation of Greek hotels, Journal of Hospitality and Tourism Marketing, 11 (2/3), 83-97.

Sirgy, M.J. \& Su, C. (2000). Destination image, self-congruity, and travel behavior: Toward an integrative model. Journal of Travel Research. 38. 340-352.

Stephano, R. \& Edelheit, J. (2009). The future of medical tourism. Medical Tourism Magazine. 8. 10-15.

Wan, C.S. (2002). The web sites of international tourist hotels and tour wholesalers in Taiwan, Tourism Management, 23, 155-160.

Wasserman, E. (2002). Trade in health services in the region of the Americas. WHO: Trade in Health Services. 
Weiermair, K., \& Mathies, C. (2004). The Tourism and Leisure Industry: Shaping the Future. New York: Haworth Hospitality Press.

Woodman, J. (2008). Patients beyond borders: Everybody's guide to affordable, world-class medical tourism. Chapel Hill, NC: Healthy Travel Media. 